\title{
Description of Long Term Outcome of Sublingual Immunotherapy Treat- ment in Children: A Follow-Up Observation Through Phone Interviews
}

\author{
Steiner $\mathrm{L}^{1}$, Engel $\mathrm{T}^{2}$, Nöding $\mathrm{A}^{1}$, Licht $\mathrm{M}^{3}$, Delaney $\mathrm{A}^{1}$, Distler $\mathrm{A}^{4}$, Zwacka $\mathrm{G}^{5}$ and Markert $\mathrm{UR}^{1, *}$ \\ ${ }^{I}$ Placenta-Lab, Department of Obstetrics, Friedrich-Schiller-University, Jena; ${ }^{2}$ Institute for Sociology, Friedrich- \\ Schiller-University, Jena; ${ }^{3}$ Private Clinic, Saalfeld, Germany; ${ }^{4} H A L$-Allergie GmbH, Düsseldorf; ${ }^{5}$ Children's Hospital, \\ Robert-Koch-Hospital, Apolda, Germany
}

\begin{abstract}
Background: Efficacy of sublingual immunotherapies (SLIT) is mostly demonstrated during or immediately after the therapy, but little is reported about long-term efficacy.

Patients and Methods: 121 phone interviews were performed to analyze the state of patients after SLIT. All patients were children who were treated in two centers in Germany. Questionnaires were developed and standardized with respect to statistical and social rules. 19 questions were designed to elucidate the subjective estimation of allergic symptoms (conjunctivitis, rhinitis, asthma, atopic dermatitis), duration of therapy (> 2 years), duration of preexisting allergy, type of allergen, symptomatical medication, age, gender and others before starting SLIT, immediately after SLIT and 1 to 6 years after having finished the therapy. All interviews were conducted with the patients' mothers. Due to ethical considerations, for this period of up to 9 years after initiation of treatment, formation of a placebo control group was impossible.

Results: In summary, the general state of health improved significantly in $93 \%$ of all patients during therapy. This was similar for all single symptoms. During the period after therapy, $84 \%$ of patients did not feel any worsening of their state and $15 \%$ reported a very slight return of symptoms. At the same time, no patient felt worse than before initiating SLIT, and $8 \%$ felt similar to the state before. Results were equal 1, 3 and 5 years after termination of SLIT.

Conclusion: In comparison to the expectable allergic march, which implicates a high risk of intensifying symptoms in untreated patients, SLIT treated patients improved and demonstrated a long-lasting clinical effect (5 years) of the therapy. Rates of improvements are higher than spontaneous remissions (age dependently, $5-25 \%$ ) as reported in previous studies.
\end{abstract}

Keywords: Sublingual Immunotherapy, allergy, long-term efficacy, asthma, dermatitis, rhinoconjunctivitis, phone interviews.

\section{INTRODUCTION}

Efficacy of sublingual immunotherapy (SLIT) is demonstrated by an increasing number of studies, and therefore, an interesting alternative to subcutaneous immunotherapy (SCIT) [1]. These effects are mostly demonstrated during or immediately after the therapy, but very little is scientifically reported about long-term efficacy, especially in children [2]. SLIT is presently used in many European countries. This kind of treatment has several advantages over subcutaneous immunotherapy (SCIT) because the risks of severe adverse events are reduced and the treatment is performed by the patients themselves at home, and therefore, very well accepted by the patients.

SLIT was developed from the oral allergy treatment. This treatment was described by Curtis in 1900 [3]. The lack of efficacy was the main reason why the oral treatment was declined as a treatment for clinical practice as presented in the WHO Position Paper, Allergen Immunotherapy [4]. the same paper, SLIT was described as a "may be" viable alternative to parenteral injection therapy. SLIT may be used for adults with allergic rhinitis, but there was insufficient evidence to use it for children.

*Address correspondence to this author at the Abteilung für Geburtshilfe, Friedrich-Schiller-Universität, D-07740 Jena, Germany; Tel: +49/ 3641 / 933763; Fax: +49/ 3641 / 933764; E-mail: markert@med.uni-jena.de; www.placenta-labor.de
Since 1996, the number of SLIT-studies has been growing rapidly. Investigators have proposed two alternative routes of allergen administration: sublingual spit or sublingual swallow. The sublingual spit method was used in earlier studies and entails the vaccine to be kept under the tongue for some minutes and then spat out. However, the majority of the studies used the sublingual swallow method, which is presently considered the more advantageous and appropriate way to administer the allergen. A study that investigated the pharmacokinetics of the two techniques demonstrated that the sublingual spit method led to a partial loss of allergen [5].

\section{SLIT Studies}

The Cochrane meta-analysis from Wilson analyzed the efficacy and safety of SLIT in treatment of rhinitis in 22 studies with 979 patients [6]. They found a significant reduction in both symptoms and medication requirements following SLIT.

In a comprehensive review from Cox, different aspects of SLIT were discussed [7]. Four studies were found which compared SLIT with SCIT. A literature search conducted by Malling using Medline identified 39 placebo-controlled, double-blind sublingual studies [8]. Clinical efficacy was estimated according to statistical significance and graded as unequivocal efficacy. 
The long term efficacy of SLIT in adults and children is one of the most important open questions on SLIT. Di Rienzo published data from this prospective open study in 2003 in which children with asthma due to house dust mites were studied for a period up to five years after discontinuation of SLIT [9]. Studies on long-term efficacy from patients treated with pollen extracts via the sublingual method are not readily available and therefore provided motivation for the present investigation.

Our study presents data from patients who had SLIT treatment for three years and were then re-evaluated up to a period of six years after treatment. The method used for this analysis consists of phone interviews, which allow a record of the subjective self-estimation of symptoms' severity and history. An advantage of phone interviews is that patients can be contacted and included in the investigations, who due to loss of complaints do not visit their doctors anymore. Especially children who have been treated against allergies by their pediatrician have frequently changed their doctors. SLIT.

The results demonstrate a long-lasting clinical effect of

\section{PATIENTS AND METHODS}

\section{Patients}

121 patients' parents (in the further text termed as "patients" for better readability) were successfully contacted and included into the study. At the beginning of their treatment, all patients were children $(5-18$ years of age, mean age: 11.23 years, standard error: 0.27 years) and all were treated with Sublivac BEST (HAL-Allergie GmbH, Germany) at the Pediatrics Department of the Robert-Koch-Hospital Apolda $(n=75)$ or a private pediatrics clinic in Saalfeld $(n=46)$. The preparation was applied perennially, three days a week, kept for two minutes under the tongue and swallowed. Patients were selected exclusively by their duration of therapy, which was calculated by numbers and dates of prescriptions. A minimum of two treatment seasons was an inclusion requirement. Patients were asked for earlier immunotherapies. A positive answer led to exclusion. $40.37 \%$ of patients were girls and $59.63 \%$ boys. All patients had a positive allergy history with a CAP class of 3 or higher and had respective symptoms (rhinocojunctivitis, asthma, dermatitis or combinations thereof). Treatments were performed against tree pollen, grass pollen and mite allergies. No further selection has been performed and all available patients from both clinics have been included.

Twelve patients reported that they did not perform the therapy regularly, although they have received their medication during two seasons. The interviews were not continued with these patients. It remains uncertain if they told the truth or if they wanted to avoid the interview. 109 out of the 121 contacted patients were included and phone interviews were performed completely. The interval between end of therapy and interview was up to 6 years. 21 patients did not yet pass an allergy season after finishing the therapy. $44 \%$ of the remaining patients passed 1 or 2 seasons, $46 \%$ passed 3 seasons and $28 \%$ passed 4 to 6 seasons (Table $\mathbf{1}$ ).

A total of 88 interviewed patients fulfilled the including criteria for analysis of long-term effects (at least one allergy
Table 1. Interval after finishing therapy. All patients $(n=88)$ have experienced at least one season after the end of therapy. "1 year" means interval from 0.5 to 1.5 years and so on.

\begin{tabular}{|c|c|}
\hline $\begin{array}{c}\text { Years After } \\
\text { Therapy }\end{array}$ & \% Patients \\
\hline \hline$<0.5$ & 8 \\
\hline 1 & 9 \\
\hline 2 & 9 \\
\hline 3 & 46 \\
\hline 4 & 18 \\
\hline 5 & 8 \\
\hline 6 & 2 \\
\hline
\end{tabular}

season experienced after having finished SLIT). All following calculations and data are based on these patients.

\section{Interviews}

All interviews were given by the patients' parents, except two patients who were over 20 years at the time of the interview. They confirmed to remember their allergy history well. Duration of interviews was approximately 15 -20 minutes. All interviews were done by one single person (Dr. Liane Steiner, former doctoral student at the Friedich-SchillerUniversity, Jena). There was no dependency between her and the company and no dependency of results of the study and quotation of her thesis. For interviewing and statistical analysis, a standardized questionnaire was developed and used strictly.

\section{Questionnaire}

Questionnaires were developed and standardized with the cooperation of medical, social and statistical scientists. In contrast to guidelines-based questionnaires, standardized questionnaires implicate the same questions and prepared answering options for all persons to be interviewed. 19 questions plus several sub-questions were designed to analyze the state of allergic symptoms at various time points, but also to control the credibility of provided information. All communications were conducted in German.

The following questions were asked:

1. For how long did your child have allergic symptoms before starting SLIT?

2. Against which allergens did your child react with symptoms? (this information was compared with the clinicians information)

3. During which months did your child display symptoms?

4. Did your child receive a subcutaneous immunotherapy before SLIT?

5. When did your child start and finish SLIT? Did your child take the drops regularly? 
For further questions, a scoring system was used in concordance with German school notes, which was easily understood for everybody: "1" means "very good", "6" means "very bad".

6. How was the general state of allergy before starting SLIT?

7. How was the general state of allergy immediately after SLIT?

8. How is the general state of allergy now?

9. A. How was the state of conjunctivitis before starting SLIT?

B. How was the state of conjunctivitis immediately after SLIT?

C. How was the state of conjunctivitis during the last pollen season?

D. How is the current state of conjunctivitis in the case of perennial allergy?

- Additionally, at all 4 sub-questions, the need of medications was asked to be rated.

10.-12. Same schemes for rhinitis, asthma and atopic dermatitis

13. How do you estimate the changes of general state of allergy and use of medication of your child?

14. How was the tolerability of the medication?

15. Would you recommend the same therapy to other patients?

16. Why was the therapy finished? (possible answers: the physician's decision; side effects; patient/parents decide therapy is successfully finished; patient/parents declined treatment; pregnancy; change of doctor or city; other reasons)

17. Has your child developed new allergies since finishing SLIT?

18. Do you feel a need for a new SLIT treatment?

19. How did you inform yourself when you heard your child had an allergy?

Recent evaluations of the telephone interview method by our group (using the same score system as here from 1 to 6 ) have resulted in high consistency and reliability of answers on self-assessment of state of allergy before and shortly after treatment. For this analysis, 100 patients (not identical with those patients who have been interviewed here) have been contacted twice with a mean interval of 19 months in between. Similar to the investigation presented in this manuscript, patients have been asked for the general state of allergy, conjunctivitis, rhinitis, asthma and dermatitis before and after an immunotherapy. The statistical analysis has been performed by calculating intra-class- correlation coefficients which revealed a very high reliability of results of the phone interview questionnaire. Details of this analysis and the method validation will be published elsewhere. An exemplary result was that patients scored their state of allergy before therapy as 4.1 (mean; $\mathrm{n}=100$; expected statistical mean of the score system 3.5). The discrepancy of the results

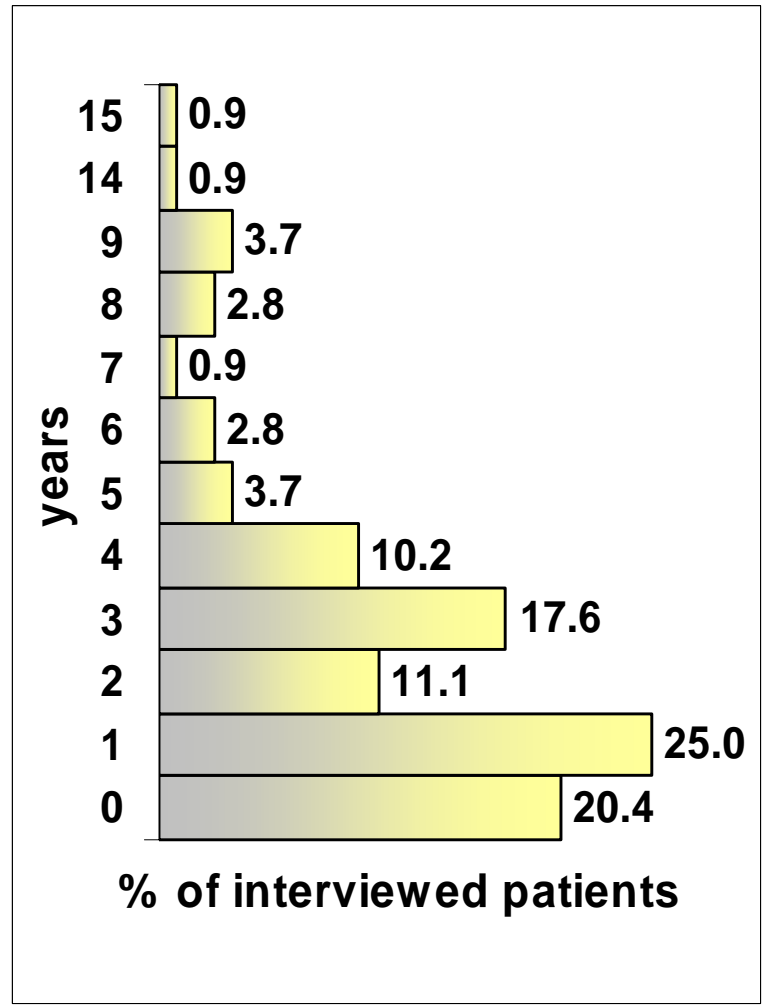

Fig. (1). Subjectively estimated interval of years with allergic symptoms before starting SLIT $(n=109)$.

19 months later was below 0.15 scores (increase). When individual symptoms have been asked, the discrepancy did never exceed this value. When general state of allergy or individual symptoms immediately after therapy have been scored, a significant improvement has been observed, but the discrepancy between first and second interview has been always within the same range $(<0.15$ scores $)$. Summarized, the method has been validated on 100 patients and 10 questions each. The discrepancy of the mean scores for identical questions after an interval of 19 months was always < 0.15 (unpublished data).

\section{Statistics}

For statistical evaluation, a test of marginal homogeneity has been performed. This test evaluates and compares scores obtained for the different treatment phases (before, after and at interview). The use of medication (yes or no) at different time points was compared by using the McNemar test.

\section{RESULTS}

\section{Interval Between First Onset of Symptoms and Initiation of Therapy}

$20.4 \%$ of patients reported they started SLIT the same year when symptoms were noted the first time. $63.9 \%$ of patients had allergic symptoms from 1 to 4 years before they started SLIT and $15.7 \%$ of patients waited up to 15 years until starting the therapy (Fig. 1). As for all other questions, this was a subjective self-estimation and the onset of allergic symptoms was, in most cases, not diagnosed by a physician. There was no dependency of long-term efficacy and duration of symptoms before therapy (data not shown). 


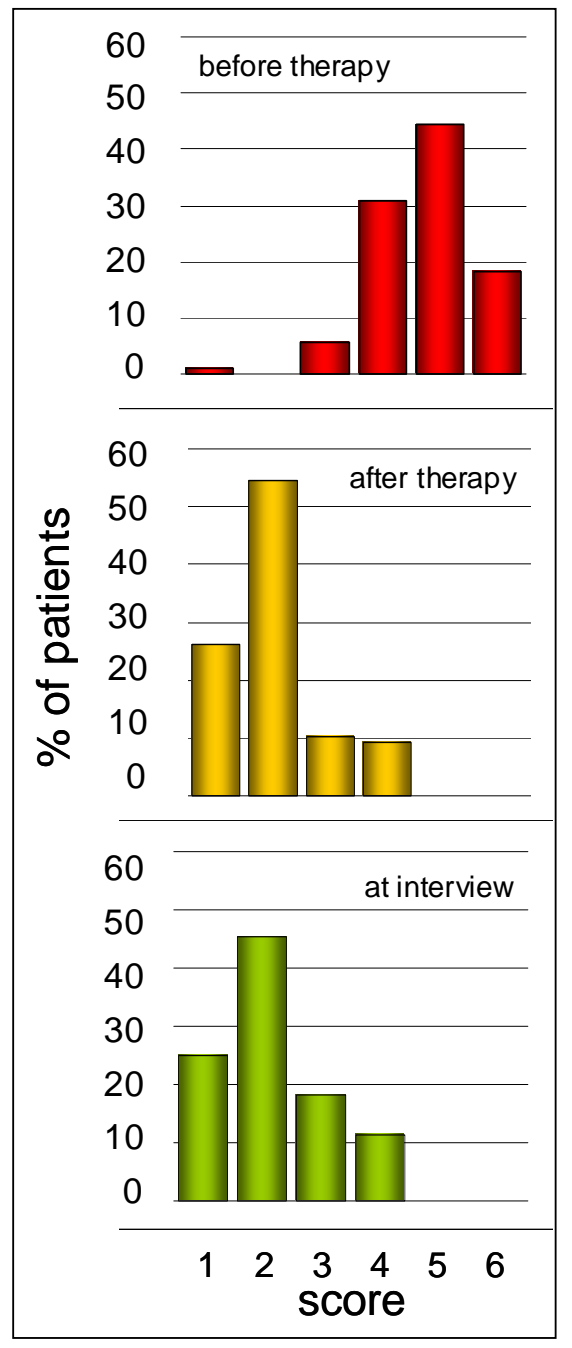

Fig. (2). Patients at least one season after finishing SLIT $(n=88)$ estimated their general state of allergic symptoms. "1" - no symptoms; "6" very bad symptoms, the others gradually in between, respectively. Scoring was performed according to German school notes system (for before:after therapy and before therapy:at interview $\mathrm{p}<0.05$; after therapy:at interview no significant difference; test of marginal homogeneity).

\section{Allergen Specificity, Symptom Season and Duration of Therapy}

Patients were asked for allergen specificity and have remembered the following: trees $n=42$; grasses $n=75$; herbs $\mathrm{n}=11$, mites $\mathrm{n}=54$; molds $\mathrm{n}=8$; animals $\mathrm{n}=7$; food $\mathrm{n}=8$; others $\mathrm{n}=2$. The self-estimation for inhalation allergies coincided by $>95 \%$ with the medical records.

\section{General Evaluation of Allergic Symptoms}

$90 \%$ of patients reported a score of 4,5 or 6 during the seasons before starting SLIT. 9\% of patients estimated a score of 3 and 1 patient did not feel any symptoms (score 1). This patient reported that the diagnosis of allergy occurred occasionally and his physician recommended a SLIT treatment to prevent future symptoms. Immediately after SLIT, no patient asserted a score of 5 or 6 , but $84 \%$ of patients had a score of 1 to 2 (Fig. 2). No patient indicated an occurrence of symptoms becoming worse during therapy, $9 \%$ did not feel any change and $91 \%$ felt improvement at different levels. The improvement of the score was significant $(p<0.05$, test of marginal homogeneity). During the interval between finishing SLIT and the interview, $84 \%$ of patients did not notice any changes or even further improvement. Comparison of time spans between finishing SLIT and the interview did not reveal remarkable differences. $86 \%$ of patients, at least 3 years after termination of SLIT, did not feel worse and $89 \%$ of patients, for at least 5 years after SLIT (Table 2). Concerning the general use of additional symptomatic allergy medication during the year before the interview, $97 \%$ of patients reported reduction compared to the time before initiating the therapy (Table 3a). For detection of possible age dependency of long-term effects, 3 patient groups were compared: 6 years or younger, 7 to 12 years and 13 years or older. In the youngest group, $73 \%$ of patients reported an improvement from before therapy to the year before the interview, in the middle group $90 \%$ and in the oldest group 91\% (detailed data not shown). This difference was not significant.

\section{Conjunctivitis and Rhinitis}

In the scoring system between 1 (excellent) and 6 (very bad), no patient estimated their conjunctivitis symptoms before SLIT better than 3. Immediately after SLIT and during the last year or season, no patient scored worse than 4, which means a significant improvement $(\mathrm{p}<0.05$, test of marginal homogeneity). The self-estimation of patients with perennial allergy was slightly better than those with seasonal allergies - none of those scored worse than 3 (Fig. 3). Results and significances were similar with regards to rhinitis symptoms. Before SLIT, $58 \%$ of patients scored 5 or worse; whereas after SLIT and during the last year or from then on, no patient scored 5 or worse. Best scores were obtained from patients with perennial allergies, who scored exclusively 1,2 or 3 for the last year (Fig. 3).

The use of medication for conjunctivitis and rhinitis symptoms decreased significantly during SLIT and remained at a stable level until the interview ( $\mathrm{p}<0.05$, McNemar test; Table 3).

\section{Asthma}

54 patients suffered from asthmatic symptoms before initiating SLIT. $76 \%$ of these patients scored them with 5 or 6 . Immediately after therapy and during the last season or year, more than $80 \%$ of patients scored 1 or 2 . One single patient with perennial asthma scored 6 for the last year before the interview, but no other patient reported a score worse than 4 (improvement: $\mathrm{p}<0.05$, test of marginal homogeneity; Fig. 3). $95 \%$ of these patients used medication against asthma before starting SLIT, but only 37\% used medication immediately after having finished SLIT ( $<<0.05$, McNemar test). During the interval after SLIT, the use of asthma medication was further reduced in both groups, seasonal and perennial symptoms (Table $\mathbf{3}$ ).

\section{Atopic Dermatitis}

Before SLIT, $57 \%$ of patients scored 4 or worse, but none after SLIT and during the last year. Patients with perennial allergies scored exclusively 1 or 2 for the last year, the 
Table 2. Differences of patients' subjective scoring of general allergic symptoms between different time points and depending on interval after finishing therapy. Scoring system from 1 to 6 according to German school notes: 1 - no symptoms; 6 - very bad symptoms, the other scores in between, respectively. Difference " +1 " means improvement by one score and so on. It needs to be considered that grade of maximal improvement depends upon initial score (e.g. when initial score was 4 , a maximal improvement of 3 is possible; $n=88$ ).

\begin{tabular}{|c|c|c|c|c|c|}
\hline & $\begin{array}{l}\text { Change of } \\
\text { Score }\end{array}$ & $\begin{array}{c}\text { Before: } \\
\text { After Therapy }\end{array}$ & $\begin{array}{c}\text { After Therapy: Interview } \\
\text { 1-3 Seasons }\end{array}$ & $\begin{array}{c}\text { After Therapy: Interview } \\
\text { 3-5 Seasons }\end{array}$ & $\begin{array}{c}\text { After Therapy: Interview } \\
>\text { 5 Seasons }\end{array}$ \\
\hline & -3 & 0 & 1 & 0 & 0 \\
\hline & -2 & 0 & 1 & 0 & 0 \\
\hline & -1 & 0 & 15 & 14 & 11 \\
\hline \multirow[t]{7}{*}{ no change } & no change & 9 & 77 & 81 & 67 \\
\hline & +1 & 10 & 5 & 5 & 11 \\
\hline & +2 & 15 & 1 & 0 & 11 \\
\hline & +3 & 37 & 0 & 0 & 0 \\
\hline & +4 & 27 & 0 & 0 & 0 \\
\hline & +5 & 2 & 0 & 0 & 0 \\
\hline & & $\%$ of patients & $\%$ of patients & $\%$ of patients & $\%$ of patients \\
\hline
\end{tabular}

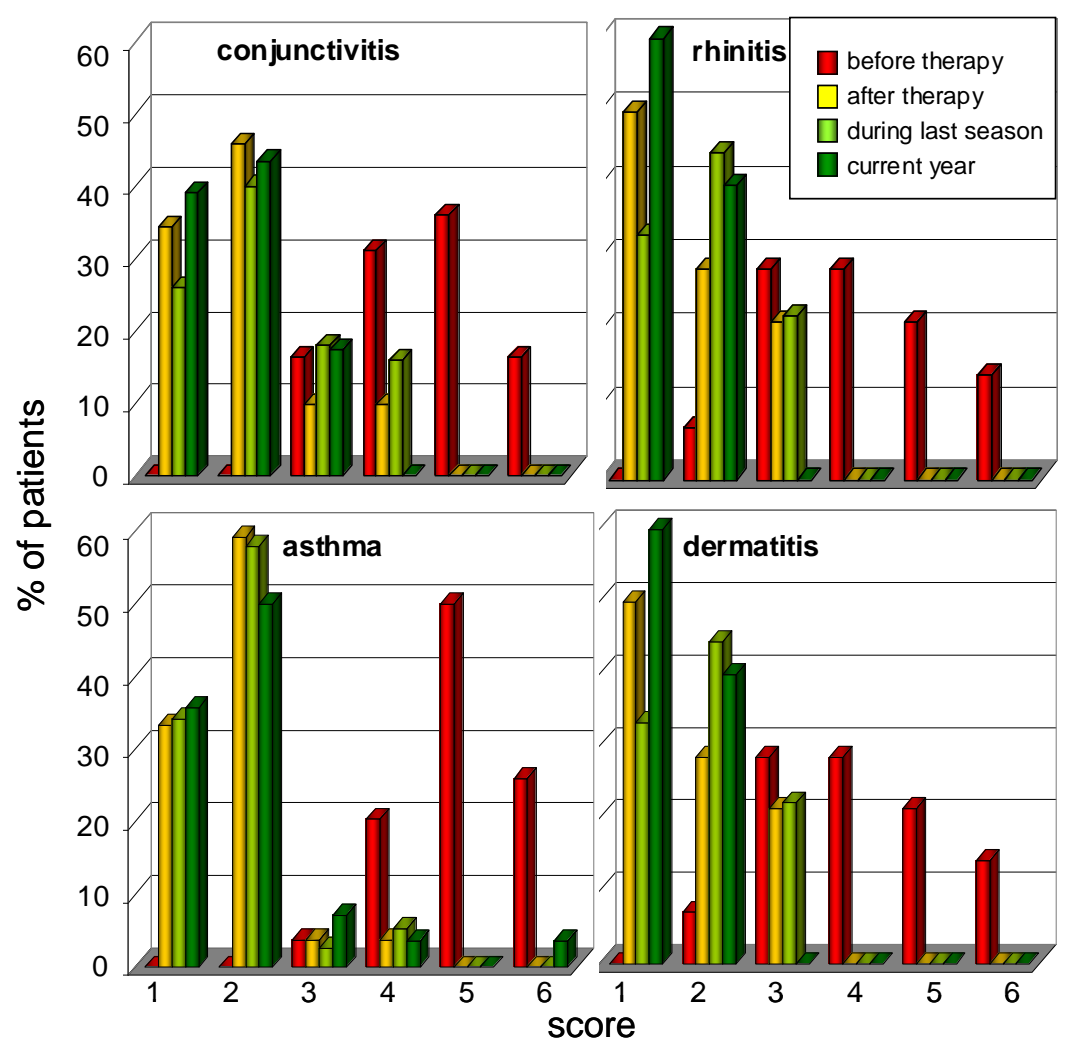

Fig. (3). Patients at least one season after finishing SLIT who remembered allergic conjunctivitis $(n=61)$, rhinitis $(n=71)$, asthma $(n=54)$ or dermatitis $(n=14)$ estimated a) their state of each symptom. "1" - no symptoms; "6" very bad symptoms, the others gradually in between, respectively (for all groups before therapy compared with any other $\mathrm{p}<0.05$; test of marginal homogeneity).

others scored 1-3 (improvement: $\mathrm{p}<0.05$, test of marginal homogeneity; Fig. 3). While $86 \%$ of patients applied symptomatic medication for atopic dermatitis before SLIT, $86 \%$ did not need such medication after SLIT $(\mathrm{p}<0.05$, McNemar test). During the last season and year before the interview, $22 \%$ and $10 \%$ used symptomatic medication, respectively (Table 3).

\section{Tolerability and Side Effects of SLIT}

Patients were asked how they tolerated SLIT in regards to side effects. The following score was offered for selection: 1. excellent, no side effects; 2. good, slight side effects; 3 . moderate side effects; and 4 . bad, not acceptable. $85 \%$ rated "excellent" and 12\% "good". 3\% of patients reported moderate side effects but no patient rated "bad". 
Table 3. a) Patients at least one season after finishing SLIT estimated the change of need of symptomatic allergy medication from the time before starting SLIT until current year/season before interview. The reduction was significant $(p<0.05$, McNemar test). b) Need of symptomatic medication for treatment of individual symptoms: conjunctivitis $(n=61)$, rhinitis $(n=71)$, asthma $(n=54)$ or dermatitis $(n=14)$. The use of medication was significantly reduced at all time points and for all symptoms in comparison with "before therapy" ( $p<0.05$, McNemar test)

\begin{tabular}{|c|c|c|c|c|c|}
\hline \multicolumn{7}{|c|}{ Need of medication at Interview Compared with Before Therapy } \\
\hline & No need anymore & Significantly reduced & Reduced & Increased & Uncertain \\
\hline \hline$\%$ of patients & 49 & 32 & 16 & 2 & 1 \\
\hline
\end{tabular}

Table 3a

\begin{tabular}{|c|c|c|c|c|}
\hline Need of Medication & Conjunctivitis & Rhinitis & Asthma & Dermatitis \\
\hline \hline before therapy & 80 & 92 & 95 & 37 \\
\hline after therapy & 25 & 20 & 34 & 22 \\
\hline during last season & 36 & 6 & 25 & 10 \\
\hline during last year & 5 & & \% of patients \\
\hline
\end{tabular}

Table 3b

\section{Estimation of Recommendation Level}

$82 \%$ of interviewed parents would recommend SLIT to other patients, $14 \%$ would not and $4 \%$ are uncertain.

\section{Termination of Therapy}

Most patients (77\%) terminated SLIT as recommended by their doctor. $20 \%$ finished therapy earlier (but after at least 2 years of treatment which was inclusion criteria for this analysis) because they felt free of symptoms. They interpreted this state as no need of further continuation. $1 \%$ of patients finished therapy because they changed their doctor and $2 \%$ because they did not tolerate side effects (local itching).

\section{New Allergies After Finishing SLIT}

When parents were asked about new allergies of their children after the termination of SLIT, 3\% answered their child had developed new sensitization. This has not always been confirmed by an allergist and includes different allergies, such as those against food ingredients or metals.

\section{Need of New Treatment}

$65.9 \%$ of patients feel completely cured at the time of interview without need of new treatment. $34.1 \%$ would initiate a new SLIT. The large majority considers this for elimination of slight remaining symptoms, but not due to reestablished severe symptoms.

\section{DISCUSSION}

In comparison to the expectable allergic march, which means a high risk for intensifying symptoms in untreated patients [10], SLIT treated patients improved and showed a long-lasting clinical effect of the therapy in this study. The patients' self-assessment scores demonstrated improvement of symptoms immediately after treatment and 1 to 6 years ( 6 years: $2 \%$ of patients) after discontinuation of treatment.
Additionally, the use of medication for treatment of symptoms was reduced.

The major problem of this observational investigation is the lack of a control group. Since the total duration of this observation was up to 8 years (including therapy and posttherapy intervals), we were unable to build a non-treated, placebo or exclusively symptomatically treated group with the same symptom constellation as the investigated group before starting SLIT. Also study designs as used in shorter period studies, which included one year of placebo application, are not useful for this long-term observation [11]. Therefore, we consider the formerly described and well accepted "allergic march" as an indirect control for our investigation, well knowing that also spontaneous improvements or remissions occur $[10,12]$. By using a questionnaire also based on self-estimation of allergy rhinitis symptoms, distributed by postal mail, Nihlen has found that between 1992 and 2000 the total prevalence of allergies in a group of 9316 subjects increased from $20.5 \%$ to $25 \%$. In contrast to our investigation only adults (20-59 years, at the beginning of the 8 years period) have been included. The spontaneous remission rate was age dependent and lowest in the youngest age group (approx. 18\%; mean over all ages: 23.1\%) [12]. A few further studies have reported similar remission rates in allergic rhinitis: $17 \%$ remission of all types of allergies (12\% remission in pollen allergies) was reported in an another 8 years observation on 734 patients [13], and only 5\% and $10 \%$ remission in males and females, respectively, in a 4 years study [14]. These 3 studies did not indicate if patients which received any kind of immunotherapy have been excluded or not. Another follow-up study on 82 of the patients (40 women, 42 men; mean age 36 years), who had not received immunotherapy, was also based on a questionnaire concerning the status of their allergic rhinitis, and any development of the disease during the interim of 11-14 years. Only one patient was free of allergic symptoms and 39\% had improved; symptoms were unchanged in $39 \%$ of cases, and 
worse in $21 \%$ [15]. All previously reported spontaneous improvement and remission rates are clearly lower than those in our investigation. Therefore, we conclude that the observed improvements are due to the effects of SLIT.

To our best knowledge, the here presented is one of the most detailed and largest long-term efficacy investigation on SLIT which includes seasonal allergies. Di Renzo, in his 10year study (up to 5 years after SLIT discontinuation), also demonstrated on 35 treated children SLIT to have longlasting effects as well [9]. In this study the use of anti-asthma drugs, peak expiratory flow rate and asthma severity have been investigated. This study did not include assessment of rhinoconcunctivits and the respective use of symptomatic medications. Furthermore, SLIT treatment was exclusively against perennial mite allergies, while in our investigation, various seasonal allergy specifities have been included. Another long-term efficacy study on SLIT has been published in German, but patients have been treated with another preparation (Oralvac, Bencard-Allergie GmbH, Germany) [16]. The results are similar to the ones presented here. Furthermore, a dissertation thesis based on phone interviews of patients treated with Pangramin SLIT (Scherax-Allergie $\mathrm{GmbH}$, Germany), which was accepted by the University of Jena has shown long-term efficacy up to 10 years [17]. Differences between the treated populations and the time span between therapy and interview in all mentioned investigations do not allow comparison of efficacy of the different treatments and preparations.

Other studies have proven SLIT clinically effective with 1 to 3 years of treatment. Ozdemir et al. recently published data from a study, which demonstrated a 3-year treatment of SLIT to be effective in reducing symptoms and drug therapy for children with house dust-mite allergies [18]. As well, Marogna et al. studied over 500 subjects who were treated with SLIT for 3 years and found an improvement in symptoms as well as a reduction of onset of new sensitizations [19]. Pajno et al. also studied long-term treatment of SLIT (2-year treatment period) in children with respiratory allergies and found similar results, namely reduction in respiratory symptoms associated with asthma [20]. Several excellent reviews and meta-analyses provide an overview of international clinical studies on SLIT [6-8, 21-23]. Some reviews remind lacking information on efficacy and safety of SLIT in children [24]. Our results demonstrate very good acceptance, compliance safety and long-term effects in this patients group.

SIT, administered subcutaneously, has already been proven for its long-term effectiveness in a variety of studies. These studies have also shown how SIT vaccines can alter the natural course of the allergic disease by slowing or stopping the progression of the allergic march [25-27]. Two follow-up studies of the PAT study, conducted by Jacobsen and Niggemann, observed the same group of subjects treated with SIT for a 3-year period at 5 and 10 years after initial treatment $[28,29]$. Their results were a significant reduction and prevention of asthma and its development over time, thus proving the long-lasting clinical and preventative effect of SIT.

The method used in our study comprised of telephone interviewing, and the reliability of data can be seen in how the questionnaire was developed. The questionnaire was detailed yet remained short enough to keep the attention of the subject. The sequence of questions allowed the patient to recall information for subsequent questions. Also, the use of a standard recognized scoring system was helpful in providing the self-assessment of symptoms. Other studies using the same method, but with a different questionnaire, have demonstrated valid results [30].

This study provided scientific evidence for clinical longlasting effects of Sublivac BEST SLIT for at least 5 years. The patients' self-estimation was a good tool in assessing 'real-life' effectiveness of SLIT treatment. The results suggest that SLIT provides a non-invasive alternative for treating rhinitis, conjunctivitis, asthma and atopic dermatitis.

\section{ACKNOWLEDGMENT}

We thank the company HAL Allergie GmbH (Germany) for their friendly cooperation. There was no financial support for this study.

\section{REFERENCES}

[1] Canonica GW, Passalacqua G. Noninjection routes for immunotherapy. J Allergy Clin Immunol 2003; 111: 437-48.

[2] Halken S, Lau S, Valovirta E. New visions in specific immunotherapy in children: an iPAC summary and future trends. Pediatr Allergy Immunol 2008; 19: 60-70.

[3] Curtis HH. The immunizing cure of hay fever. Med News (NY) 1900; 77: 16-8.

[4] Bousquet J, Lockey R, Malling HJ. Allergen immunotherapy: therapeutic vaccines for allergic diseases. A WHO position paper. J Allergy Clin Immunol 1998; 102: 558-62.

[5] Passalacqua G, Villa G, Altrinetti V, et al. Sublingual swallow or spit? Allergy 2001; 56: 578.

[6] Wilson DR, Lima MT, Durham SR. Sublingual immunotherapy for allergic rhinitis: systematic review and meta-analysis. Allergy 2005; 60: 4-12.

[7] Cox LS, Linnemann DL, Nolte H, Weldon D, Finegold I, Nelson HS. Sublingual immunotherapy: a comprehensive review. J Allergy Clin Immunol 2006; 117: 1021-35.

[8] Malling HJ. Sublingual immunotherapy: efficacy--methodology and outcome of clinical trials. Allergy 2006; 61: 24-8.

[9] Di Rienzo V, Marcucci F, Puccinelli P, et al. Long-lasting effect of sublingual immunotherapy in children with asthma due to house dust mite: a 10-year prospective study. Clin Exp Allergy 2003; 33: 206-10.

[10] Wahn U. What drives the allergic march? Allergy 2000; 55: 591-9.

[11] Marcucci F, Sensi L, Di Cara G, et al. Three-year follow-up of clinical and inflammation parameters in children monosensitized to mites undergoing sub-lingual immunotherapy. Pediatr Allergy Immunol 2005; 16: 519-26.

[12] Nihlen U, Greiff L, Montnemery P, et al. Incidence and remission of self-reported allergic rhinitis symptoms in adults. Allergy 2006; 61: 1299-304.

[13] Bodtger U, Linneberg A. Remission of allergic rhinitis: An 8-year observational study. J Allergy Clin Immunol 2004; 114: 1384-8.

[14] Broder I, Higgins MW, Mathews KP, Keller JB. Epidemiology of asthma and allergic rhinitis in a total community, Tecumseh, Michigan. IV. Natural history. J Allergy Clin Immunol 1974; 54: 100-10.

[15] Danielsson J, Jessen M. The natural course of allergic rhinitis during 12 years of follow-up. Allergy 1997; 52: 331-4.

[16] Langbein B, Steiner L, Engel T, Zwacka G, Markert UR. Langzeitwirkung der sublingualen Immuntherapie bei Allergien - Eine Langzeit-Studie mittels Telefon-Interviews. Haut 2007; 18: 81-4.

[17] Hegenbarth M. Langzeitbeobachtung von Allergikern nach Sublingualer Immuntherapie. Jena: Friedrich-Schiller-Universität 2007.

[18] Ozdemir C, Yazi D, Gocmen I, et al. Efficacy of long-term sublingual immunotherapy as an adjunct to pharmacotherapy in house dust mite-allergic children with asthma. Pediatr Allergy Immunol 2007; 18: 508-15. 
[19] Marogna M, Spadolini I, Massolo A, Canonica GW, Passalacqua G. Randomized controlled open study of sublingual immunotherapy for respiratory allergy in real-life: clinical efficacy and more. Allergy 2004; 59: 1205-10.

[20] Pajno GB, Morabito L, Barberio G, Parmiani S. Clinical and immunologic effects of long-term sublingual immunotherapy in asthmatic children sensitized to mites: a double-blind, placebocontrolled study. Allergy 2000; 55: 842-9.

[21] Morris DL, Kroker GF, Sabnis VK, Morris MS. Local immunotherapy in allergy. Chem Immunol Allergy 2003; 82: 1-10.

[22] Cox L. Sublingual immunotherapy and allergic rhinitis. Curr Allergy Asthma Rep 2008; 8: 102-10.

[23] Saporta D. Sublingual immunotherapy: a novel, albeit not so new, immunotherapy treatment modality. Am J Rhinol 2008; 22: 253-7.

[24] van Wijk RG. Sublingual immunotherapy in children. Expert Opin Biol Ther 2008; 8: 291-8.

[25] Eng PA, Reinhold M, Gnehm HP. Long-term efficacy of preseasonal grass pollen immunotherapy in children. Allergy 2002; 57: $306-12$.
[26] Marogna M, Falagiani P, Bruno M, Massolo A, Riva G. The allergic march in pollinosis: natural history and therapeutic implications. Int Arch Allergy Immunol 2004; 135: 336-42.

[27] Moller C, Dreborg S, Ferdousi HA, et al. Pollen immunotherapy reduces the development of asthma in children with seasonal rhinoconjunctivitis (the PAT-study). J Allergy Clin Immunol 2002; 109: 251-6.

[28] Niggemann B, Jacobsen L, Dreborg S, et al. Five-year follow-up on the PAT study: specific immunotherapy and long-term prevention of asthma in children. Allergy 2006; 61: 855-9.

[29] Jacobsen L, Niggemann B, Dreborg S, et al. Specific immunotherapy has long-term preventive effect of seasonal and perennial asthma: 10-year follow-up on the PAT study. Allergy 2007; 62: 943-8.

[30] Gunnarsson N, Marklund B, Ahlstedt S, Borell L, Nordstrom G. Allergy-like conditions and health-care contacts among children with exclusion diets at school. Scand J Caring Sci 2005; 19: 46-52.

(c) Steiner et al.; Licensee Bentham Open.

This is an open access article licensed under the terms of the Creative Commons Attribution Non-Commercial License (http://creativecommons.org/licenses/by-nc/3.0/) which permits unrestricted, non-commercial use, distribution and reproduction in any medium, provided the work is properly cited. 